\title{
Speed-density functional relationship for heterogeneous traffic data: a statistical and theoretical investigation
}

\author{
Hari Krishna Gaddam ${ }^{1}$ K. Ramachandra Rao ${ }^{1}$
}

Received: 1 October 2016/Revised: 19 November 2018/Accepted: 21 November 2018/Published online: 5 December 2018

(C) The Author(s) 2018

\begin{abstract}
This study is an attempt to establish a suitable speed-density functional relationship for heterogeneous traffic on urban arterials. The model must reproduce the traffic behaviour on traffic stream and satisfy all static and dynamic properties of speed-flow-density relationships. As a first attempt for Indian traffic condition, two behavioural parameters, namely the kinematic wave speed at jam $\left(C_{\mathrm{j}}\right)$ and a proposed saturation flow $(\lambda)$, are estimated using empirical observations. The parameter $C_{\mathrm{j}}$ is estimated by developing a relationship between driver reaction time and vehicle position in the queue at the signalised intersection. Functional parameters are estimated using Levenberg-Marquardt algorithm implemented in the $\mathrm{R}$ statistical software. Numerical measures such as root mean squared error, average relative error and cumulative residual plots are used for assessing models fitness. We set out several static and dynamic properties of the flow-speed-density relationships to evaluate the models, and these properties equally hold good for both homogenous and heterogeneous traffic states. From the numerical analysis, it is found that very few models replicate empirical speed-density data traffic behaviour. However, none of the existing functional forms satisfy all the properties. To overcome the shortcomings, we proposed two new speed-density functional forms. The uniqueness of these models is that they satisfy both numerical accuracy and the properties of fundamental diagram. These new forms
\end{abstract}

K. Ramachandra Rao

rrkalaga@civil.iitd.ac.in

Hari Krishna Gaddam

harikrishnagaddam@gmail.com

1 Department of Civil Engineering, Indian Institute of Technology, Delhi, Hauz Khas, New Delhi, Delhi 110016, India would certainly improve the modelling accuracy, especially in dynamic traffic studies when coupling with dynamic speed equations.

Keywords Heterogeneous traffic - Speed-density model · Kinematic wave speed · Traffic flow · CURE plots

\section{Introduction}

Speed-density $(v-k)$ relationship is straightforward and easy to explain when compared to other fundamental relationships. It is a one-to-one relationship between the driver behaviour and the number of vehicles present on the road. Speed-density relationship is also a part of traffic dynamics studies [1-3] to explore traffic flow patterns such as shock waves and queue lengths on highways and urban arterials. Selection of a suitable speed-density relationship influences the performance of macroscopic traffic flow models. A functional relationship is said to be accurate when it suitably represents the empirical data and satisfies all the properties of flow-speed-density relationships. This study is an attempt to analyse the existing speed-density functional forms for their numerical accuracy and properties. Further, new models have been proposed to overcome the limitations of the existing models.

Heterogeneous traffic mixes are the common sight of appearance in all the developing economies including India. The behaviour of heterogeneous traffic mix on urban arterials is described in various studies [4-6]. In brief, the traffic streams comprise small and highly manoeuvrable vehicles such as motorised two wheelers (MTW) and motorised three-wheelers (MThW). They continuously search for the gaps in the stream to move downstream even in the congested condition, which is described as creeping 
behaviour. Highway capacity is greatly affected by widely varying physical and dynamical characteristics of vehicles in addition to the absence of lane discipline. There is a significant difference between the behaviour of homogenous and heterogeneous traffic streams. Thus, it is interesting to study the relationship between traffic stream variables under heterogeneous traffic flow conditions and the functional forms that represent it.

The main objective of this paper is to evaluate the various functional forms using statistical techniques and the properties of flow-speed-density $(q-v-k)$ relationships. Based on the results, new mathematical speed-density functional forms are proposed to improve the accuracy. This study considers only the single-regime-based models (continuously differentiable functions for the entire density range).

\section{Literature review}

\subsection{Traffic stream models}

Significant contributions have been made in developing single-regime stream models since its inception in 1935 [7]. The models are categorised into linear, logarithmic, exponential and logistic functional forms (Table 1). To start with, linear models are the simplest of all the functional forms and they are developed based on the assumption that stream speed decreases linearly with density. May and Keller's [8] model is the general form of all the linear models, and it contains boundary parameters such as free flow speed $\left(v_{\mathrm{f}}\right)$, jam density $\left(k_{\mathrm{j}}\right)$ and shape parameters $m$ and $n$ (here $m>0, n>0$ ). Other models such as those by Greenshields et al. [7], Drew [9] and Pipes [10] can be retrieved from the general form by substituting $m=1$ and/or $n=1$. The shape parameters $m$ and $n$ are

Table 1 Speed-density functional relations

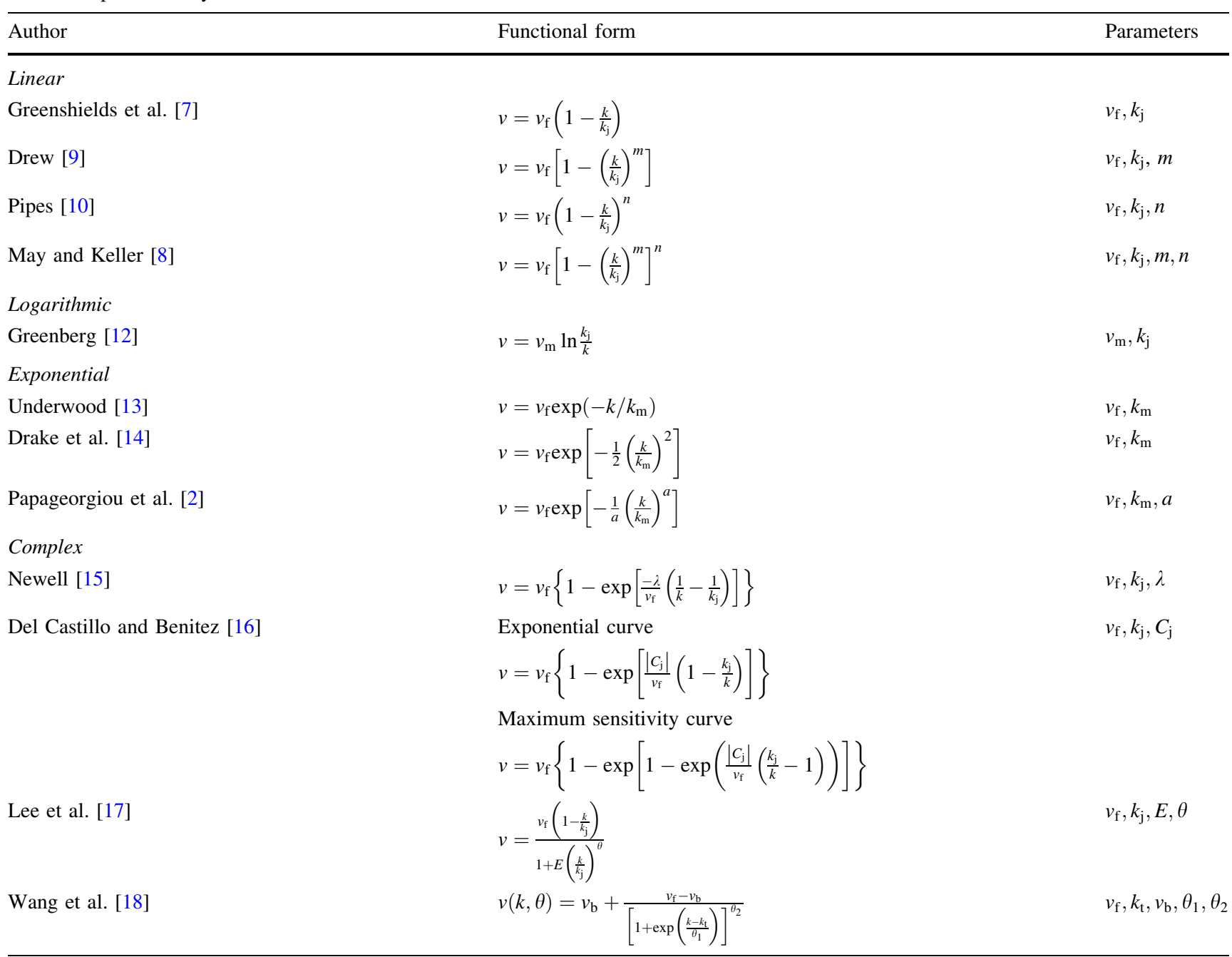


deduced from the car following theories, and they represent environment and type of the facility [11].

Logarithmic form of traffic stream model is introduced by Greenberg [12], which is derived using hydrodynamic principles. The parameters involved in this model are optimum speed $\left(v_{\mathrm{m}}\right)$ and $k_{\mathrm{j}}$, and both are difficult to observe from the field data. Besides this, the model produces infinite speed at free flow conditions. In comparison, exponential forms in the literature such as $[2,13,14]$ are robust in terms of representing empirical data and satisfying the properties of flow-speed-density relationships. Newell's [15] model is derived from the nonlinear car following theories, and it uses proportionality factor $\lambda$ in modelling traffic flow. The parameter $\lambda$ is a function of the relative speed, the intervehicle distance which is estimated by drawing the tangent to speed vs spacing curve at $v(t)=0$. Del Castillo and Benítez [16] believed that the traffic flow behaviour is strongly characterised by kinematic wave speed of vehicles at jam density $\left(C_{\mathrm{j}}\right)$. From the literature, it is observed that for various traffic facilities the $C_{\mathrm{j}}$ value is ranging from -25 to $-15 \mathrm{~km} / \mathrm{h}$. They introduced two functional forms similar to Newell's: one is the exponential curve (single exponential form) and the other one is a generalised sensitive curve (double exponential form). The estimation procedure for $C_{\mathrm{j}}$ and $\lambda$ is discussed in Sect. 3.2.

Some recent developments are Lee et al.'s [17] rational model and Wang et al.'s [18] logistic model. Lee et al.'s [17] model is made up of the following four parameters $v_{\mathrm{f}}$, $k_{\mathrm{j}}, E$ and $\theta$; and the model is developed to capture the dynamic behaviour of the traffic flow occurring at the highway ramps. For the given facility, estimated values for the shape parameters $E$ and $\theta$ are 100 and 4, respectively. Wang et al.'s [18] model is a 5 parameter logistic speeddensity relationship which is developed using 100 stations data on GA 400 expressway in Atlanta. The data used in this modelling look asymptotic to the axis at upper and lower limbs. In the given formula, $v_{\mathrm{f}}$ and $v_{\mathrm{b}}$ are the upper and lower asymptotes of the curve. Here $v_{\mathrm{b}}$ is the average travel speed at saturation region (stop and go). In the given model, $k_{\mathrm{t}}$ is the inflection point where the curve turns from free flow to congested flow, $\theta_{1}$ is a scale parameter and $\theta_{2}$ is a lop-sidedness of the curve.

From the literature survey, it is believed that research on the development of suitable speed-density functional relationship for Indian traffic condition is limited. Recently, Thankappan and Vanajakshi [19] tried to evaluate different combinations of single and two-regime models for heterogeneous traffic data collected on urban roads. The study suggested that two-regime models are better in representing the speed-density data. However, the study has only considered simple linear and exponential models for evaluation purpose and the models are not evaluated for the properties of flow-speed-density relationships.

\subsection{Properties of the speed-density and flow-density functional relationships}

To model traffic flow precisely, every stream model must satisfy the properties of flow-speed-density $(q-v-k)$ relationships. Mathematical properties are categorised into static and dynamic one. Static properties assume traffic flow as a stationary phenomenon and dynamic properties are important while studying the continuity of traffic flow. The static properties can be stated as follows:

(i) $v(k)_{k \rightarrow 0}=v_{\mathrm{f}}$.

(ii) $v^{\prime}(0)=0$; i.e., vehicles move at free flow speed when interaction between vehicles is negligible.

(iii) $v(k)_{k \rightarrow k_{\mathrm{j}}}=0$; i.e., vehicles stop at jam density.

(iv) $0<k \leq k_{\mathrm{j}}$; i.e., density varies from zero to maximum density.

(v) $0 \leq v \leq v_{\mathrm{f}}$; i.e., speed varies between zero and maximum flow possible.

(vi) Speed decreases with density, i.e. $v^{\prime}(k)<0$.

The first dynamic property is that the kinematic wave speed $\left(C_{\mathrm{j}}\right)$ of the traffic at jam condition must be a negative constant $\left(q^{\prime}(k)_{k \rightarrow k_{\mathrm{j}}}\right.$ is a negative constant). This is introduced by Del Castillo and Benítez [16], to represent shock propagation in saturation flow region. The second essential dynamic property is that flow-density $(q-k)$ relation must be convex when traffic is approaching the jam density, which is necessary for producing stable shock waves at congested conditions. This is explained below. In Heydecker and Addison [20] terms, if the flow-density relationship is concave throughout its domain (i.e. when $\left.q^{\prime \prime}(k)<0\right)$, then stable shock waves can only occur as transitions from low to high density. However, if the fundamental relationship has a subdomain within which it has a positive curvature (i.e. where $q^{\prime \prime}(k)>0$ ), then stable start waves can arise when traffic accelerates from a region with density in this subdomain to a region of lower density.

\section{Data collection and parameter estimation}

One of the objectives of this study is to fit and evaluate speed-density functional forms for heterogeneous traffic data. Empirical data are the basis for development and validation of traffic flow models. The section describes traffic data collection and variable estimation procedure under non-lane based heterogeneous traffic environment. This section also presents vehicle composition and their physical dimensions and further parameter estimation from empirical data. 


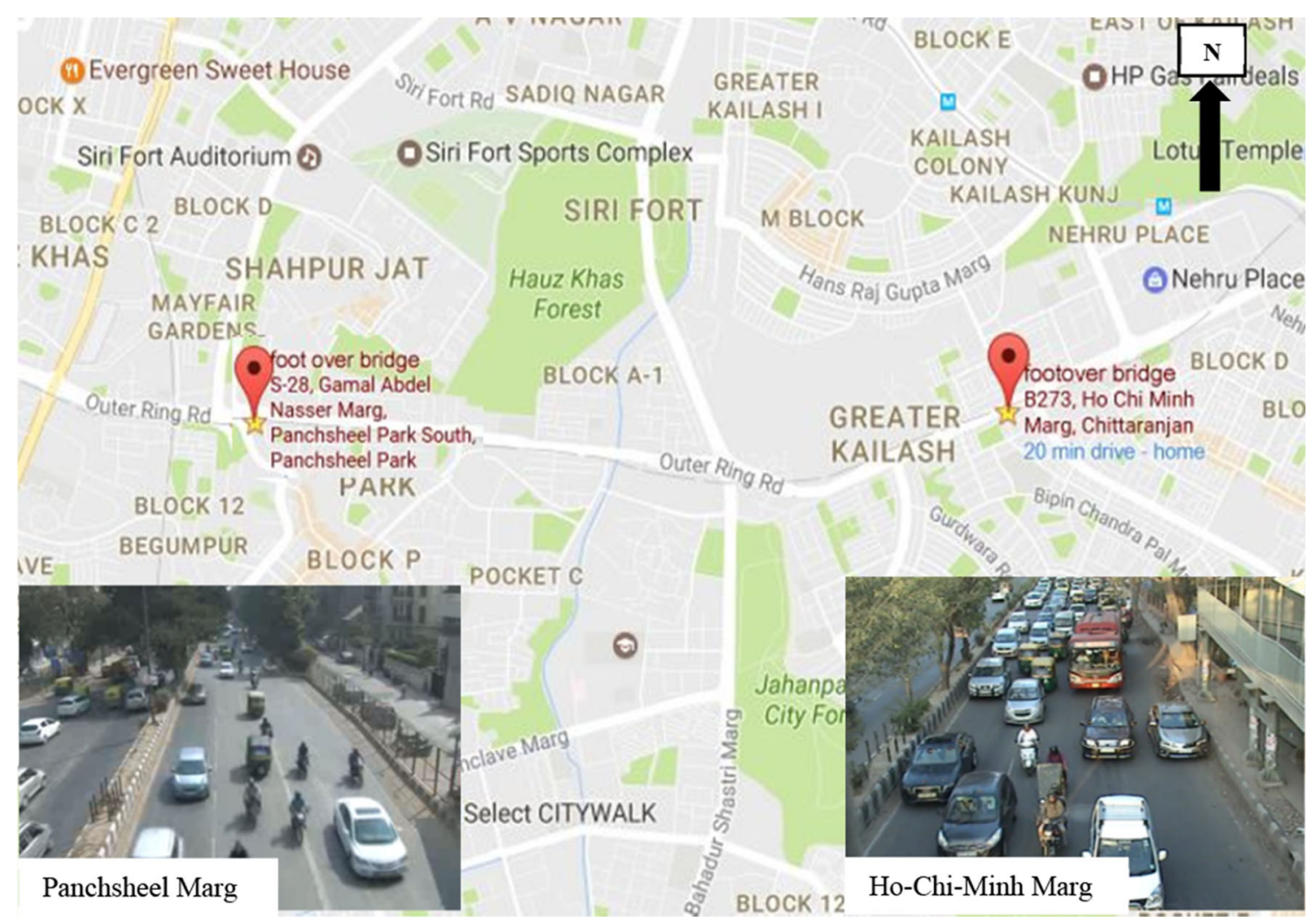

Fig. 1 Study location details

\subsection{Empirical speed-flow data}

Traffic data used in the present analysis were collected on two urban arterial sections: Panchsheel Marg $\left(28^{\circ} 32^{\prime} 35.5^{\prime \prime} \mathrm{N}, 7^{\circ} 12^{\prime} 45.8^{\prime \prime} \mathrm{E}\right)$ and Ho-Chi-Minh Marg $\left(28^{\circ} 32^{\prime} 37.3^{\prime \prime} \mathrm{N}, 7^{\circ} 14^{\prime} 39.9^{\prime \prime} \mathrm{E}\right)$ located in Delhi, India (Fig. 1). In these sections, road width is $10.5 \mathrm{~m}$ (effective width is $10 \mathrm{~m}$ ) in each direction and the gradients are negligible. Day-long class-specific speed-flow data were obtained using video cameras. Approximately $12 \mathrm{~h}$ of data (7:30 a.m. to 6:30 a.m. at Panchsheel Marg and 4:30 p.m. to 6:00 p.m. at Ho-Chi-Minh Marg) were collected on 3 March 2016 and 9 March 2016.

Due to the absence of lane discipline and presence of multiple classes of vehicles, extracting heterogeneous traffic data, especially speed profile of each vehicle over section, is cumbersome. In the present study, TRAZER ${ }^{\circledR}$ [21], a video image processing software, was used to extract individual vehicular speeds and classified volume counts. The entire width of the road is considered as a single lane, and all the vehicles have similar right of way. Vehicles are categorised into four groups based on their physical and dynamic characteristics: Cars, MTW, MThW and heavy vehicles (HV). Typical composition of vehicles and their physical and speed characteristics are provided in Fig. 2 and Table 2, respectively. Traffic stream characteristics are mainly influenced by the presence of cars and two wheelers. Stream space mean speeds and flows were obtained for each 1-min intervals using appropriate methods. Here, flow is the number of vehicles observed per minute and flow rate is the number of vehicles per hour. Speed is the weighted average speed of all classes of vehicles observed in $1 \mathrm{~min}$, and the density is the number of vehicles per kilometre estimated using fundamental relationship. The maximum flow rate observed was $11,760 \mathrm{veh} / \mathrm{h}$, and the maximum speed observed in free flow condition was $67 \mathrm{~km} / \mathrm{h}$. The equations used for estimating stream variables are given in Eqs. (1) to (5). The response of the traffic stream, i.e. space mean speed of vehicles, needs to be studied with respect to the number of vehicles present on the road. This is to ensure the true behaviour of the vehicles on the traffic stream. Therefore, flow and density are measured in veh/h and veh/ $\mathrm{km}$ instead of PCU/h and PCU/km, respectively.

Total number of vehicles per minute:

$q_{\min }=\sum_{i=1}^{N} q_{i}, \quad \forall i=1,2,3,4$,

where $i$ indicates the vehicle type and $j$ the number of vehicles in each vehicle class.

Flow rate (veh/h): 


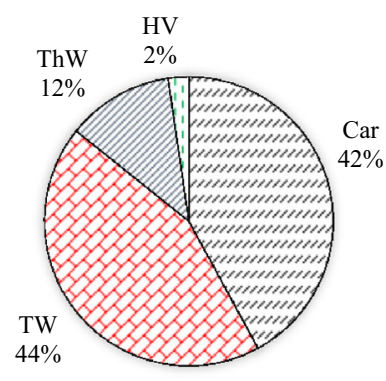

(a)

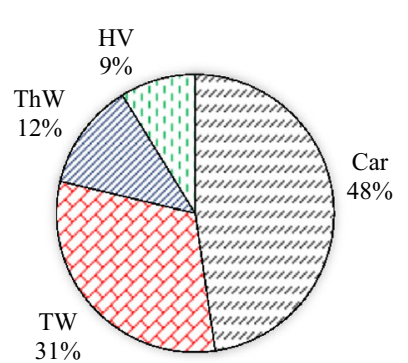

(b)
Fig. 2 Vehicle composition in terms of percentage: a Panchsheel Marg. b Ho-Chi-Minh Marg

$q_{\mathrm{hour}}=q_{\mathrm{min}} \times 60$.

Class specific harmonic mean speed $(\mathrm{km} / \mathrm{h})$ :

$v_{i}=\frac{1}{\sum_{j=1}^{M} \frac{1}{v_{j}}}, \quad \forall i=1,2,3,4 \quad$ and $\quad \forall j=1,2,3, \ldots, M$.

Weighted average speed for the stream $(\mathrm{km} / \mathrm{h})$ :

$\bar{v}=\frac{\sum_{i=1}^{N} N_{i} \times V_{i}}{\sum_{i=1}^{N} N_{i}}, \quad \forall i=1,2,3,4$.

Vehicle density (veh/km):

$k=\frac{q_{\text {hour }}}{\bar{v}}$.

The relationship between traffic stream variables is depicted in Fig. 3. The scatter plot shows that the relationship is nonlinear and the speed-density relation showing some asymptotic behaviour at the free flow and congested region. This behaviour can be attributed to the independent behaviour of vehicles at low- and high-density regions.

\subsection{Parameters from empirical observations}

For fitting and evaluating the traffic stream models, parameters observed from the field data are required. The empirical observations are also used as initial parameters in optimisation tool. Since the behaviour of heterogeneous traffic is different to that of the homogenous traffic, estimating some of the parameters mentioned in Table 1 is difficult. For instance, jam density $\left(k_{\mathrm{j}}\right)$ is a function of vehicle headway maintenance, traffic composition and road width. Likewise, kinematic wave speed $\left(C_{\mathrm{j}}\right)$ is a function of vehicle length plus safety distance and driver reaction time. There will be a wide variation in the above-mentioned parametric values due to the following reasons. Vehicles are positioned close to each other in the same lane, and the gaps between large vehicles will be filled by the smaller ones. In addition, urban traffic composition in India shows that there are at least ten classes of vehicles observed on the roads where vehicle lengths vary from $1.8 \mathrm{~m}$ (MTW) to $10.3 \mathrm{~m}$ (Bus) and the safety distances maintained by these vehicles are very small. Therefore, jam density is not constant (suitable value will be considered for the typical composition) for a given road section. Moreover, the estimation of $C_{\mathrm{j}}$ will also be challenging. Now the parameter estimation procedure will be discussed under this section. It is believed that the macroscopic relationship of traffic flow is strongly characterised by some of the important parameters such as kinematic wave speed at jam density $\left(C_{\mathrm{j}}\right)$ and saturation flow parameter $(\lambda)$. In microscopic scale, parameter $\lambda$ is a function of relative speed and intervehicle distance. However, in macrolevel, it is a function of kinematic wave speed and jam density of vehicular flow. The parameter $C_{\mathrm{j}}$ is a disturbance propagation speed of the vehicles when density is approaching the jam density and it is a function of vehicle length plus safety distance and driver reaction time. It is a first attempt to estimate these parameters for Indian traffic condition. The detailed estimation procedure is given below.

\subsubsection{Kinematic wave speed $\left(C_{j}\right)$ estimation}

It is well known that $C_{\mathrm{j}}$ value can be estimated by studying vehicle dynamics at the signalised intersection [16]. Stopping and starting waves can be observed at signals during the green and red time, and it resembles the vehicular

Table 2 Vehicle classes, physical dimensions and speed characteristics

\begin{tabular}{|c|c|c|c|c|c|c|}
\hline \multirow[t]{2}{*}{ Vehicle class } & \multirow[t]{2}{*}{ Vehicles included } & \multirow[t]{2}{*}{ Vehicle average dimensions (m) } & \multicolumn{4}{|c|}{ Speed characteristics $(\mathrm{km} / \mathrm{h})$} \\
\hline & & & $v_{\text {free }}$ & $v_{\text {cong }}$ & $v_{\text {mean }}$ & $v_{\sigma}$ \\
\hline Car & Small car, SUV, van & $5.0 \times 2.0$ & 73.4 & 4.7 & 47 & 14.8 \\
\hline Motorised two wheeler & Scooter, moped & $1.8 \times 0.6$ & 65.2 & 7.4 & 46.5 & 12.8 \\
\hline Motorised three wheeler & Auto, LCV & $2.6 \times 1.4$ & 55.5 & 4.5 & 31 & 8.2 \\
\hline Heavy vehicles & Bus, truck & $10.3 \times 2.5$ & 52.3 & 3.5 & 29 & 9.0 \\
\hline
\end{tabular}

$S U V$ sports utility vehicle, $L C V$ light commercial vehicle, $v_{\text {free }}$ maximum free flow speed, $v_{\text {cong }}$ minimum congested speed, $v_{\text {mean }}$ mean speed, $v_{\sigma}$ standard deviation of speeds 

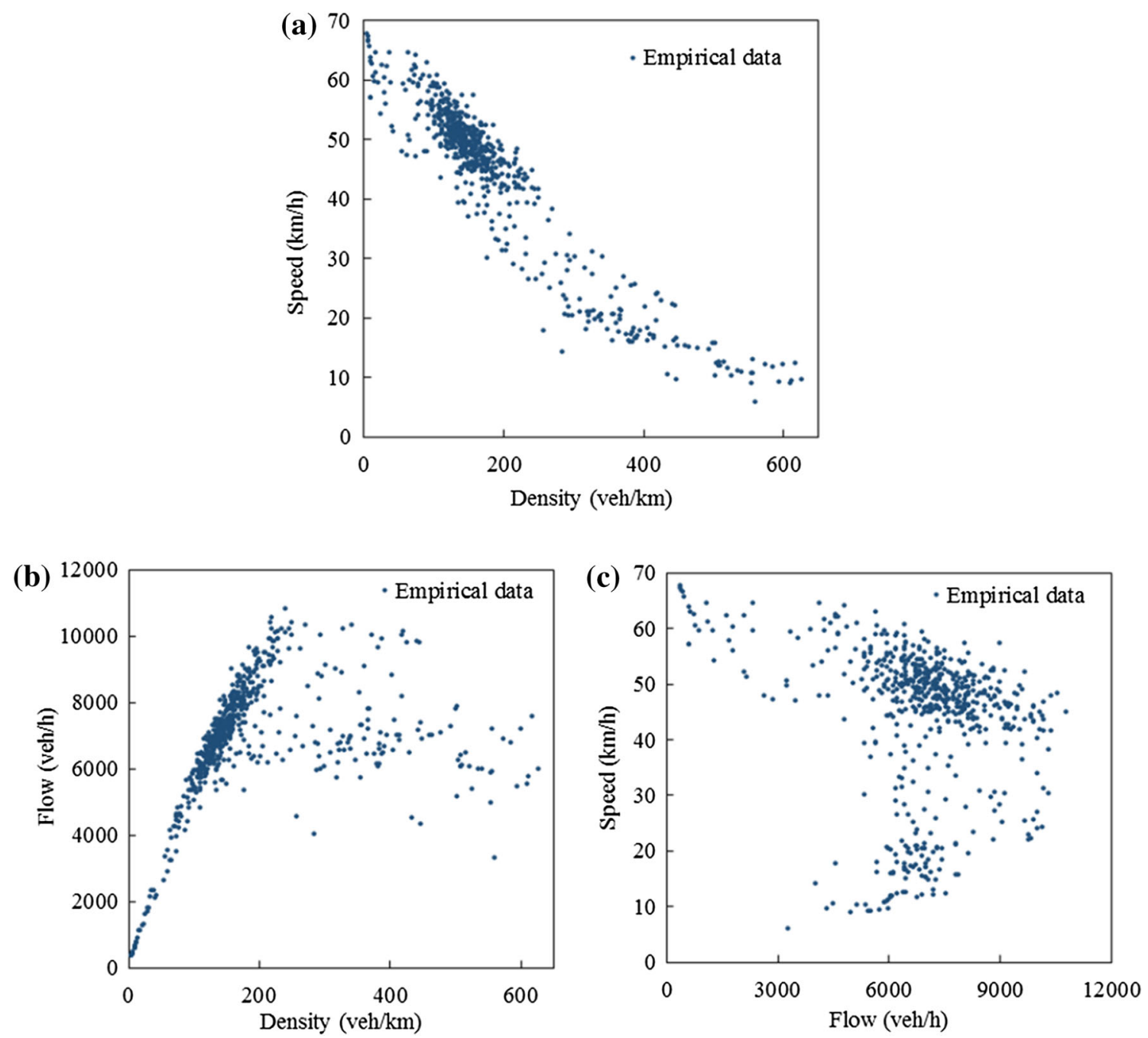

Fig. 3 Empirical relationships between a speed-density, b flow-density and $\mathbf{c}$ speed-flow data

behaviour at congestion region. Therefore, data regarding reaction time $\left(t_{\mathrm{s}}\right)$ of the different driver classes are obtained at Sri Aurobindo Marg signalised intersection $\left(28^{\circ} 32^{\prime} 40.2^{\prime \prime} \mathrm{N} 77^{\circ} 12^{\prime} 04.5^{\prime \prime} \mathrm{E}\right)$ located in Delhi, India. Here the reaction time is an elapsed time between the start of the green time and start of the vehicle in a queue.

A linear relationship [Eq. (6)] was found between the reaction time $\left(t_{\mathrm{s}}\right)$ and the vehicle position $(n)$ in a queue with proportionality variance 0.8021 . Average reaction time was found to be $1.45 \mathrm{~s}$ from this equation. The relationship between reaction time and vehicle position is shown in Fig. 4.

$t_{\mathrm{s}}=1.4517 n-0.4441$.

For a value of $5 \mathrm{~m}$ as average vehicle length (with respect to composition) plus safety distance maintained, $C_{\mathrm{j}}$ is equivalent to $-12.42 \mathrm{~km} / \mathrm{h}$ as shown in Eq. (7). This value is used in assessing various functional forms.
$C_{\mathrm{j}}=-\frac{5 \mathrm{~m}}{1.45 \mathrm{~s}}=-12.42 \mathrm{~km} / \mathrm{h}$.

\subsubsection{Estimation of $\lambda$ and other parameters}

We derived the parameter by comparing Newell's [15] and Del Castillo's [16] exponential equations. Newell's model can be rewritten as shown in Eq. (8).

$v=v_{\mathrm{f}}\left\{1-\exp \left[\frac{-\lambda}{v_{\mathrm{f}} k_{\mathrm{j}}}\left(\frac{k_{\mathrm{j}}}{k}-1\right)\right]\right\}$.

Here $-\lambda / k_{\mathrm{j}}$ represents the $C_{\mathrm{j}}$, i.e. the kinematic wave speed in Del Castillo and Benítez [16] model; therefore, $\lambda=C_{\mathrm{j}} k_{\mathrm{j}}$ and the values depend on the kinematic wave speed and the jam density. As per the empirical data, it starts from approximately 9000 and the value is equivalent to the traffic flow value in the saturation region. Therefore, it is defined as a saturation flow parameter. 


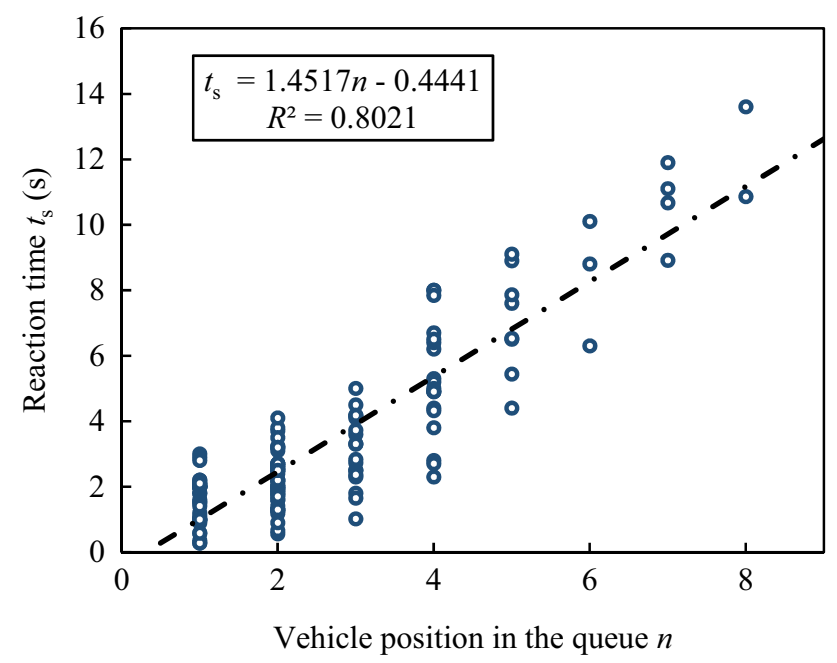

Fig. 4 Relation between driver reaction and vehicle position in the queue

Jam density $\left(k_{\mathrm{j}}\right)$ is estimated through multiple snapshots taken during the evening congestion, and the values are ranging from 700 to $800 \mathrm{veh} / \mathrm{km}$. Further, the shape parameters from different models such as $m, n, E, \theta$ and $a$, the scale parameter $\theta_{1}$, and the lop-sidedness parameter $\theta_{2}$ are unknown and they will be estimated using optimisation algorithm. Parameter values such as $v_{\mathrm{b}}$ and $k_{\mathrm{t}}$ are assumed based on the definitions given in the literature [18]. Parameters identified from the empirical data are tabulated below (Table 3).

\section{Fitting and evaluation of traffic stream models}

\subsection{Model fitting and statistical evaluation}

Model parameters are estimated using Levenberg-Marquardt (LM) algorithm [22] implemented in the R statistical software. The LM algorithm switches between GaussNewton algorithm (GNA) and the gradient descent (GD) method, and it is more robust compared to GNA and GD in finding optimal solutions. Sum of square residuals is used as an optimisation function, and the model parameter values are calibrated by minimising this function. Geometric fitting of the different speed-density models is shown in Figs. 5 and 6. Statistical measures such as the root mean squared error (RMSE) and the average relative error (ARE) as defined in Eqs. (9) and (10) are used for assessing the model's fitness. The RMSE gives you a sense of how close the observed data points are to the model's predicted values. As the square root of variance, RMSE can be interpreted as the standard deviation of the unexplained variance, and it is relatively easy to understand and communicate since reported values are in the same units as the dependent variable being modelled. This is useful in a variety of applications where the accuracy and precision of your model's predictions are important. Similarly, ARE is also used for comparing model accuracy in predicting observed data. Lower values of RMSE and ARE indicate a better fit. Parameter values and the model performance calculated using different statistical measure are presented in Table 4.

RMSE $=\sqrt{\frac{1}{N} \sum_{i=1}^{N}\left(v_{\mathrm{o}}(k)-v_{\mathrm{e}}(k)\right)^{2}}$,

$\mathrm{ARE}=\frac{1}{N} \sum_{i=1}^{N} \frac{\left|v_{\mathrm{o}}(k)-v_{\mathrm{e}}(k)\right|}{\left|v_{\mathrm{e}}(k)\right|}$,

where $v_{\mathrm{o}}(k)$ represents the empirically observed data, $v_{\mathrm{e}}(k)$ represents the model estimated value specific to particular density and $N$ represents the total number of data sets.

From the graphical and statistical measures (RMSE and ARE), it is observed that Wang et al.'s model is outperforming all the other models and the parameters also close to the empirical observations. It is followed by models of Papageorgiou et al., Lee et al. and May and Keller. However, barring Greenberg et al.'s model with the highest RMSE value and Drew's model with the highest ARE value, it is somewhat difficult to choose the model on the basis of these statistics that can outperform other models. In this regard, cumulative residual (CURE) plots [23] have been used in assessing the models' performance.

\subsection{Cumulative residual plots}

CURE plots help in assessing the model performance across the different spectrums of density regions. Long increasing and decreasing runs in CURE plots represent the underestimation and overestimation of data values, respectively. A perfect representative model gives a line

Table 3 Parameter values from empirical data

\begin{tabular}{llllllll}
\hline Parameter & $\begin{array}{l}\text { Free flow } \\
\text { speed }\left(v_{\mathrm{f}}\right) \\
(\mathrm{km} / \mathrm{h})\end{array}$ & $\begin{array}{l}\text { Optimum } \\
\text { speed }\left(v_{\mathrm{m}}\right) \\
(\mathrm{km} / \mathrm{h})\end{array}$ & $\begin{array}{l}\text { Kinematic wave } \\
\text { speed }\left(C_{\mathrm{j}}\right) \\
(\mathrm{km} / \mathrm{h})\end{array}$ & $\begin{array}{l}\text { Average travel speed at } \\
\text { saturation region }\left(v_{\mathrm{b}}\right) \\
(\mathrm{km} / \mathrm{h})\end{array}$ & $\begin{array}{l}\text { Jam } \\
\text { density } \\
\left(k_{\mathrm{j}}\right) \\
(\mathrm{veh} / \mathrm{km})\end{array}$ & $\begin{array}{l}\text { Optimum } \\
\text { density }\left(k_{\mathrm{m}}\right) \\
(\mathrm{veh} / \mathrm{km})\end{array}$ & $\begin{array}{l}\text { Inflection } \\
\text { point }\left(k_{\mathrm{t}}\right)\end{array}$ \\
\hline Value & $65-70$ & $25-30$ & -12.42 & $5-10$ & $700-800$ & $280-300$ & $150-200$ \\
\hline
\end{tabular}




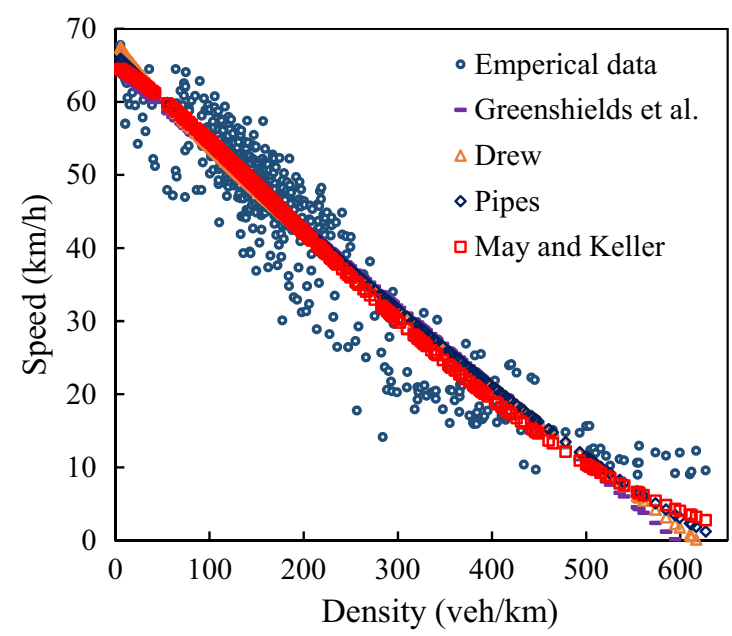

(a)

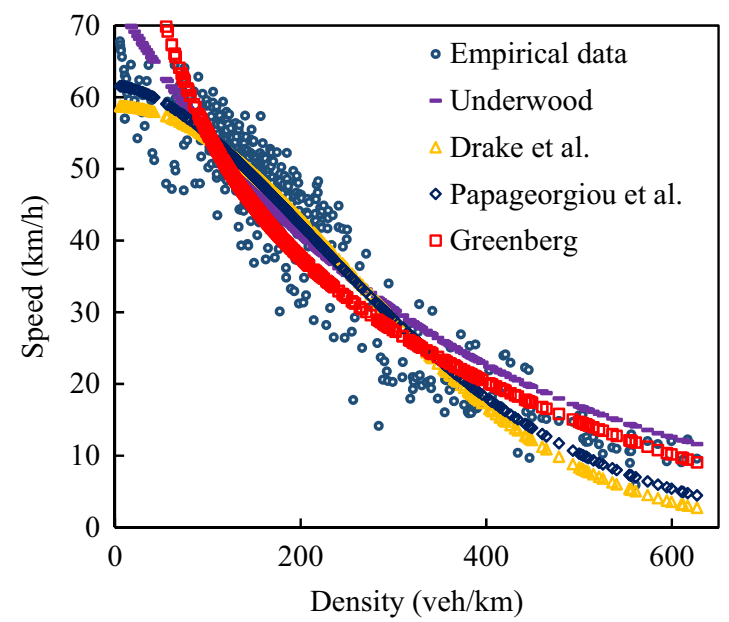

(b)

Fig. 5 Geometric fitness of the simple a linear and $\mathbf{b}$ exponential traffic stream models

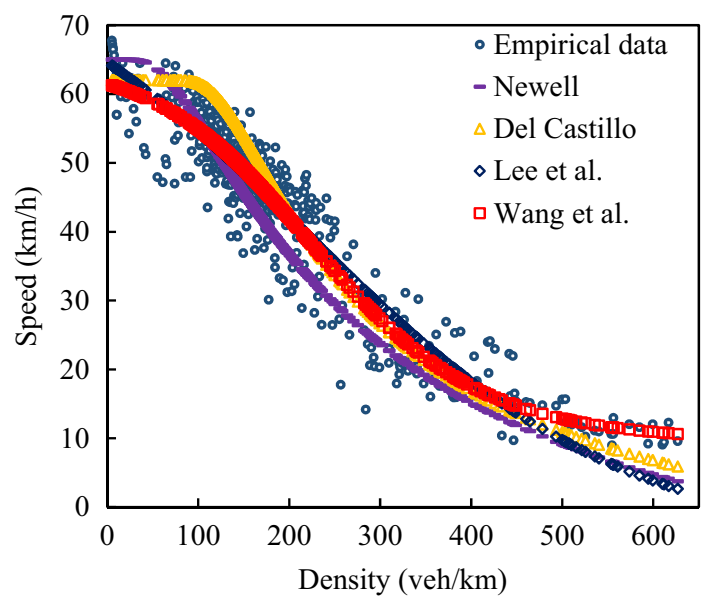

Fig. 6 Geometric fitness of the complex traffic stream models

which is meandering around the horizontal axis and their total cumulative bias must be the minimum. CURE plots in Fig. 7b, d show that Wang et al.'s and Papageorgiou et al.'s models are robust in speed predictions; their cumulative absolute bias values can be estimated [23] to be 556 and 693, respectively, which are lower than those of other functions (for example Del Castillo 2191 and Underwood 1400). Functional forms such as Lee et al.'s and Drake et al.'s are also reliable ones. The CURE plots in Fig. 7c show that the models of Greenberg et al., Newell and Del Castillo are equally good at the density greater than $200 \mathrm{veh} / \mathrm{km}$. Linear models are showing a good trend in the density range of 180-300 veh/km, as shown in Fig. 7a.

Statistical analysis and graphical presentation revealed that models involving a large number of parameters such as Wang et al.'s and Lee et al.'s are sound descriptors of empirical data. It is obvious that they resemble any kind of traffic phenomenon with some adjustments in boundary and shape parameter values. However, in Sect. 5 we will show that Lee et al.'s model accuracy can be improved further by introducing additional parameters. It is clear from the analysis that linear models of Greenshields et al., Drew and Pipes are poor in representing the data. While models of Greenbergs et al., Newell and Del Castillo can be part of multi-regime speed-density models due to their good estimation accuracy at high-density regions.

\subsection{Theoretical investigation}

On the basis of the statistical evaluation, we can converge on some models as the best candidates to represent the empirical data. This may, however, not be sufficient to ensure that these models are good in representing the behaviour of traffic flow. In this section, models will be evaluated for their static and dynamic traffic properties. Static properties of the model are derived from the fact that traffic flow is stationary and is always at equilibrium. However, properties such as the kinematic wave speed $\left(C_{\mathrm{j}}\right)$ and stable shock wave are related to the dynamic behaviour of the traffic flow and they are obtained from continuum theory of traffic flow. These properties equally hold good for both homogenous and heterogeneous traffic states. Interpretation of static and dynamic properties of the models is discussed below.

\subsubsection{Static properties of the model}

Free flow speed $\left(v(k)_{k \rightarrow 0}=v_{\mathrm{f}}\right)$ and jam speed $\left(v(k)_{k \rightarrow k_{\mathrm{j}}}=0\right)$ are the local properties of the traffic flow relationship since they define the behaviour of speed-density curve at 
Table 4 Model parameters and fitness values

\begin{tabular}{|c|c|c|c|c|c|c|c|}
\hline \multirow[t]{2}{*}{ Serial no. } & \multirow[t]{2}{*}{ Model } & \multicolumn{3}{|c|}{ Fundamental parameters } & \multirow[t]{2}{*}{ Shape parameters } & \multirow[t]{2}{*}{ RMSE } & \multirow[t]{2}{*}{ ARE } \\
\hline & & $v_{\mathrm{f}}(\mathrm{km} / \mathrm{h})$ & $k_{\mathrm{j}}(\mathrm{km} / \mathrm{h})$ & Others & & & \\
\hline 1 & Greenshields et al. & 64.57 & 596 & - & - & 4.687 & 0.312 \\
\hline 2 & Drew & 68.68 & 619 & - & $m=0.85$ & 4.612 & 0.335 \\
\hline 3 & Pipes & 66.52 & 650 & - & $n=1.2$ & 4.580 & 0.125 \\
\hline 4 & May and Keller & 64.78 & 757 & - & $m=1.23, n=2.0$ & 4.312 & 0.113 \\
\hline 5 & Greenberg & - & 900 & $v_{\mathrm{m}}=25 \mathrm{~km} / \mathrm{h}$ & - & 10.014 & 0.133 \\
\hline 6 & Underwood & 73.60 & - & $k_{\mathrm{m}}=339 \mathrm{veh} / \mathrm{km}$ & - & 4.904 & 0.101 \\
\hline 7 & Drake et al. & 58.77 & - & $k_{\mathrm{m}}=253 \mathrm{veh} / \mathrm{km}$ & - & 4.335 & 0.129 \\
\hline 8 & Papageorgiou et al. & 61.59 & - & $k_{\mathrm{m}}=260 \mathrm{veh} / \mathrm{km}$ & $a=1.7$ & 4.177 & 0.100 \\
\hline 9 & Newell & 65.00 & 750 & & $\lambda=14,761$ & 5.479 & 0.148 \\
\hline 10 & Del Castillo and Benitez & 62.00 & 891 & $C_{\mathrm{j}}=-14 \mathrm{~km} / \mathrm{h}$ & - & 5.994 & 0.120 \\
\hline 11 & Lee et al. & 64.63 & 700 & - & $E=2.1, \theta=2.5$ & 4.266 & 0.117 \\
\hline 12 & Wang et al. & 65.00 & - & $\begin{array}{l}v_{\mathrm{b}}=9.64 \mathrm{~km} / \mathrm{h} \\
k_{\mathrm{t}}=200\end{array}$ & $\theta_{1}=82.3, \theta_{2}=0.776$ & 4.033 & 0.079 \\
\hline
\end{tabular}

Table 5 Validation of static properties

\begin{tabular}{|c|c|c|c|c|c|}
\hline \multirow[t]{2}{*}{ Model } & \multicolumn{5}{|c|}{ Model static properties } \\
\hline & $\begin{array}{l}\text { Free flow property } \\
v(k)_{k \rightarrow 0}=v_{\mathrm{f}}\end{array}$ & $\begin{array}{l}\text { Independent property } \\
v^{\prime}(0)=0\end{array}$ & $\begin{array}{l}\text { Jam density property } \\
v(k)_{k \rightarrow k_{\mathrm{j}}}=0\end{array}$ & $\begin{array}{l}\text { Speed range } \\
0 \leq v \leq v_{\mathrm{f}}\end{array}$ & $\begin{array}{l}\text { Slope property } \\
v^{\prime}(k)<0\end{array}$ \\
\hline Greenshields et al. & $\sqrt{ }$ & $\mathrm{x}$ & $\sqrt{ }$ & $\sqrt{ }$ & $\sqrt{ }$ \\
\hline Drew & $\sqrt{ }$ & $\sqrt{ }$ & $\sqrt{ }$ & $\sqrt{ }$ & $\sqrt{ }$ \\
\hline Pipes & $\sqrt{ }$ & $\mathrm{x}$ & $\sqrt{ }$ & $\sqrt{ }$ & $\sqrt{ }$ \\
\hline May and Keller & $\sqrt{ }$ & $\sqrt{ }$ & $\sqrt{ }$ & $\sqrt{ }$ & $\sqrt{ }$ \\
\hline Greenberg & $\mathrm{x}$ & $\mathrm{x}$ & $\sqrt{ }$ & $\mathrm{x}$ & $\sqrt{ }$ \\
\hline Underwood & $\sqrt{ }$ & $\mathrm{x}$ & $\mathrm{x}$ & $\mathrm{x}$ & $\sqrt{ }$ \\
\hline Drake et al. & $\sqrt{ }$ & $\sqrt{ }$ & $\mathrm{x}$ & $\mathrm{x}$ & $\sqrt{ }$ \\
\hline Papageorgiou et al. & $\sqrt{ }$ & $\sqrt{ }$ & $\mathrm{x}$ & $\mathrm{x}$ & $\sqrt{ }$ \\
\hline Newell & $\sqrt{ }$ & $\sqrt{ }$ & $\sqrt{ }$ & $\sqrt{ }$ & $\sqrt{ }$ \\
\hline Delcastillo and Benítez & $\sqrt{ }$ & $\sqrt{ }$ & $\sqrt{ }$ & $\sqrt{ }$ & $\sqrt{ }$ \\
\hline Lee et al. & $\sqrt{ }$ & $\mathrm{x}$ & $\sqrt{ }$ & $\sqrt{ }$ & $\sqrt{ }$ \\
\hline Wang et al. & $\sqrt{ }$ & $\sqrt{ }$ & $\mathrm{x}$ & $\mathrm{x}$ & $\sqrt{ }$ \\
\hline
\end{tabular}

$\sqrt{ }=$ satisfied, $\mathrm{x}=$ not satisfied

extremities. Therefore, the speed values must be ranging between $v_{\mathrm{f}}$ and 0 . Another local property observed from the empirical data is that as traffic density approaches zero, the dependence of speed on density disappears, i.e. $v^{\prime}(k)_{k \rightarrow 0}=0$. The length of this region depends on the number of lanes, type of facility and composition of the vehicles. The length of the section observed in heterogeneous traffic condition is very small as shown in Fig. 3a. It is also clear from the observation that speed decreases with density, i.e. $v^{\prime}(k)<0$. Table 5 shows that except Drew, May, Newell and Delcastillo's models, none of other models satisfies all the static properties. Models of Greenshields et al., Pipes, Greenberg, Underwood and Lee et al. are violating the independent property of the model, therefore undermining their suitability in representing traffic behaviour at free flow. Further, it is also noted that models of Underwood, Drake et al., Papageorgiou et al. and Wang et al. are producing infinite speed values as density approaching jam density. It is not realistic in terms of traffic flow.

\subsubsection{Kinematic wave speed property $\left(C_{j}\right)$}

Kinematic wave speed property of models is estimated using the first-order derivative of flow equation with respect to density (as $k \rightarrow k_{\mathrm{j}}$ ). It can also be stated as a 
Table 6 Validation of dynamic properties

\begin{tabular}{|c|c|c|}
\hline \multirow[t]{2}{*}{ Model } & \multicolumn{2}{|l|}{ Model dynamic properties } \\
\hline & $\begin{array}{l}\text { Kinematic wave speed property } \\
q^{\prime}(k)_{k \rightarrow k_{\mathrm{j}}} \text { is a negative constant }\end{array}$ & $\begin{array}{l}\text { Stable shock wave property } \\
q^{\prime \prime}(k)_{k \rightarrow k_{\mathrm{j}}}>0\end{array}$ \\
\hline $\begin{array}{l}\text { Greenshields } \\
\text { et al. }\end{array}$ & $q^{\prime}(k)=v_{\mathrm{f}}\left(1-\frac{2 k}{k_{\mathrm{j}}}\right), q^{\prime}(k)_{k \rightarrow k_{\mathrm{j}}}=-v_{\mathrm{f}}$ & $q^{\prime \prime}(k)_{k \rightarrow k_{\mathrm{j}}}=\frac{-2 v_{\mathrm{f}}}{k_{\mathrm{j}}}<0$ \\
\hline Drew & $q^{\prime}(k)=v_{\mathrm{f}}\left[1-\frac{(m+1) k^{m}}{k_{\mathrm{j}}^{m}}\right], q^{\prime}(k)_{k \rightarrow k_{\mathrm{j}}}=-m v_{\mathrm{f}}$ & $q^{\prime \prime}(k)_{k \rightarrow k_{\mathrm{j}}}=\frac{-m(m+1) v_{\mathrm{f}}}{k_{\mathrm{j}}} ;$ for $m>0, q^{\prime \prime}(k)_{k \rightarrow k_{\mathrm{j}}}<0$ \\
\hline Pipes & $q^{\prime}(k)_{k \rightarrow k_{\mathrm{j}}}=-n v_{\mathrm{f}}\left(1-\frac{k}{k_{\mathrm{j}}}\right)^{n-1} ;$ for $n>1, q^{\prime}(k)_{k \rightarrow k_{\mathrm{j}}} \rightarrow 0$ & $\begin{array}{l}q^{\prime \prime}(k)=\frac{n v_{\mathrm{f}}}{k_{\mathrm{j}}}\left(1-\frac{k}{k_{\mathrm{j}}}\right)^{n-2}\left[(n+1) \frac{k}{k_{\mathrm{j}}}-2\right], q^{\prime \prime}(k)_{k \rightarrow k_{\mathrm{j}}}>0 \\
\quad \text { when } k>\frac{2}{(n+1)} k_{\mathrm{j}}\end{array}$ \\
\hline May and Keller & $\begin{array}{l}q^{\prime}(k)=\left\{v_{\mathrm{f}}\left[1-\left(\frac{k}{k_{\mathrm{j}}}\right)^{m}\right]^{n-1}\left[1-(1+n m)\left(\frac{k}{k_{\mathrm{j}}}\right)^{m}\right]\right\} \\
\quad \text { for } m>1, n>1, q^{\prime}(k)_{k \rightarrow k_{\mathrm{j}}} \rightarrow 0\end{array}$ & $\begin{array}{l}q^{\prime \prime}(k)=\frac{m n v_{\mathrm{f}}}{k_{\mathrm{j}}^{m}}\left[1-\left(\frac{k}{k_{\mathrm{j}}}\right)^{m}\right]^{n-2}\left[(m n+1)\left(\frac{k}{k_{\mathrm{j}}}\right)^{n}-(1+m)\right], \\
q^{\prime \prime}(k)_{k \rightarrow k_{\mathrm{j}}}>0 \text { when } k>\left(\frac{1+m}{m n+1}\right)^{n} k_{\mathrm{j}}\end{array}$ \\
\hline Greenberg & $q^{\prime}(k)=v_{\mathrm{m}}\left[\ln \left(\frac{k_{\mathrm{j}}}{k}\right)-1\right], q^{\prime}(k)_{k \rightarrow k_{\mathrm{j}}}=-v_{\mathrm{m}}$ & $q^{\prime \prime}(k)_{k \rightarrow k_{\mathrm{j}}}=-\frac{v_{\mathrm{m}}}{k_{\mathrm{j}}}<0$ \\
\hline Underwood & $q^{\prime}(k)=\left[v_{\mathrm{f}} \exp \left(\frac{-k}{k_{\mathrm{m}}}\right)\right]\left(1-\frac{k}{k_{\mathrm{m}}}\right) ;$ for $k \rightarrow \infty, q^{\prime}(k)=-0$ & $q^{\prime \prime}(k)_{k \rightarrow k_{\mathrm{j}}}=\frac{v_{\mathrm{f}}}{k_{\mathrm{m}}} \exp \left(\frac{-k_{\mathrm{j}}}{k_{\mathrm{m}}}\right)\left[-2+\frac{k_{\mathrm{j}}}{k_{\mathrm{m}}}\right], q^{\prime \prime}(k)_{k \rightarrow k_{\mathrm{j}}}>0$ \\
\hline Drake et al. & $\begin{array}{l}q^{\prime}(k)=\left\{v_{\mathrm{f}} \exp \left[\frac{-1}{2}\left(\frac{k}{k_{\mathrm{m}}}\right)^{2}\right]\right\}\left[1-\left(\frac{k}{k_{\mathrm{m}}}\right)^{2}\right] ; \text { for } k \rightarrow \infty \\
q^{\prime}(k)=-0\end{array}$ & $q^{\prime \prime}(k)_{k \rightarrow k_{\mathrm{j}}}=\frac{v_{\mathrm{f}} k_{\mathrm{j}}}{k_{\mathrm{m}}^{2}}\left\{\exp \left[\frac{-1}{2}\left(\frac{k_{\mathrm{j}}}{k_{\mathrm{m}}}\right)^{2}\right]\right\}\left[-3+\left(\frac{k_{\mathrm{j}}}{k_{\mathrm{m}}}\right)^{2}\right]>0$ \\
\hline $\begin{array}{l}\text { Papageorgiou } \\
\text { et al. }\end{array}$ & $\begin{array}{l}q^{\prime}(k)=\left\{v_{\mathrm{f}} \exp \left[\frac{-1}{a}\left(\frac{k}{k_{\mathrm{m}}}\right)^{\mathrm{a}}\right]\right\} \\
\quad \times\left[1-\left(\frac{k}{k_{\mathrm{m}}}\right)^{a}\right] ; \text { for } k \rightarrow \infty, q^{\prime}(k)=-0\end{array}$ & $\begin{array}{l}q^{\prime \prime}(k)_{k \rightarrow k_{\mathrm{j}}}=\frac{v_{\mathrm{f}} k_{\mathrm{j}}^{a-1}}{k_{\mathrm{m}}^{2}}\left\{\exp \left[\frac{-1}{a}\left(\frac{k_{\mathrm{j}}}{k_{\mathrm{m}}}\right)^{a}\right]\right\}\left[-(a+1)+\left(\frac{k_{\mathrm{j}}}{k_{\mathrm{m}}}\right)^{a}\right] \\
\quad \text { for } k_{\mathrm{j}}>k_{\mathrm{m}}(a+1)^{\frac{1}{a}}, q^{\prime \prime}(k)_{k \rightarrow k_{\mathrm{j}}}>0\end{array}$ \\
\hline Newell & $\begin{array}{l}q^{\prime}(k)=v_{\mathrm{f}}\left\{1-\exp \left[\left(\frac{-\lambda}{v_{\mathrm{f}}}\right)\left(\frac{1}{k}-\frac{1}{k_{\mathrm{j}}}\right)\right]\right. \\
\left.\quad-\frac{\lambda}{v_{\mathrm{f}} k}\left[\exp \left(\frac{-\lambda}{v_{\mathrm{f}}}\left(\frac{1}{k}-\frac{1}{k_{\mathrm{j}}}\right)\right)\right]\right\}, q^{\prime}(k)_{k \rightarrow k_{\mathrm{j}}}=-C_{\mathrm{j}}\end{array}$ & $q^{\prime \prime}(k)_{k \rightarrow k_{\mathrm{j}}}=\frac{-\lambda^{2}}{v_{\mathrm{f}} k_{\mathrm{j}}^{3}} \exp \left[\frac{-\lambda}{v_{\mathrm{f}}}\left(\frac{1}{k_{\mathrm{j}}}-\frac{1}{k_{\mathrm{j}}}\right)\right]=\frac{-\lambda^{2}}{v_{\mathrm{f}} k_{\mathrm{j}}^{3}}<0$ \\
\hline $\begin{array}{l}\text { Delcastillo and } \\
\text { Benítez }\end{array}$ & $\begin{array}{l}q^{\prime}(k)=v_{\mathrm{f}}\left\{1-\exp \left[\left(\frac{C_{\mathrm{j}}}{v_{\mathrm{f}}}\right)\left(1-\frac{k_{\mathrm{j}}}{k}\right)\right]\left[1+\left(\frac{C_{\mathrm{j}} k_{\mathrm{j}}}{v_{\mathrm{f}} k}\right)\right]\right\} \\
\quad \text { for } q^{\prime}(k)_{k \rightarrow k_{\mathrm{j}}}=-C_{\mathrm{j}}\end{array}$ & $q^{\prime \prime}(k)_{k \rightarrow k_{\mathrm{j}}}=\frac{-C_{\mathrm{j}}^{2}}{v_{\mathrm{f}} k_{\mathrm{j}}} \exp \left[\frac{C_{\mathrm{j}}}{v_{\mathrm{f}}}\left(1-\frac{k_{\mathrm{j}}}{k_{\mathrm{j}}}\right)\right]=\frac{-C_{\mathrm{j}}^{2}}{v_{\mathrm{f}} k_{\mathrm{j}}}<0$ \\
\hline Lee et al. & $\begin{array}{l}q^{\prime}(k)=\frac{v_{\mathrm{f}}\left\{\left[1+E\left(\frac{k}{k_{\mathrm{j}}}\right)^{\theta}\right]\left(1-\frac{2 k}{k_{\mathrm{j}}}\right)-\left[\frac{E \theta}{k_{\mathrm{j}}}\left(k-\frac{k^{2}}{k_{\mathrm{j}}}\right)\left(\frac{k}{k_{\mathrm{j}}}\right)^{\theta-1}\right]\right\}}{\left[1+E\left(\frac{k}{k_{\mathrm{j}}}\right)^{\theta}\right]^{2}}, \\
\text { for } q^{\prime}(k)_{k \rightarrow k_{\mathrm{j}}}=\frac{-v_{\mathrm{f}}}{1+E}\end{array}$ & $q^{\prime \prime}(k)_{k \rightarrow k_{\mathrm{j}}}=\frac{2 v_{\mathrm{f}}}{k_{\mathrm{j}}(1+E)}\left(\frac{E \theta}{1+E}-1\right)$, for $q^{\prime \prime}(k)_{k \rightarrow k_{\mathrm{j}}}=\frac{0.45 v_{\mathrm{f}}}{k_{\mathrm{j}}}>0$ \\
\hline Wang et al. & $\begin{array}{l}q^{\prime}(k)=v_{\mathrm{b}}+\frac{v_{\mathrm{f}}-v_{\mathrm{b}}}{\left[1+\exp \left(\frac{k-k_{\mathrm{t}}}{\theta_{1}}\right)\right]^{\theta_{2}}}-\frac{k\left(v_{\mathrm{f}}-v_{\mathrm{b}}\right) \theta_{2} \exp \left(\frac{k-k_{\mathrm{t}}}{\theta_{1}}\right)}{\theta_{1}\left[1+\exp \left(\frac{k-k_{\mathrm{t}}}{\theta_{1}}\right)\right]^{\theta_{2}+1}}, \\
\quad \text { for } k \rightarrow \infty, q^{\prime}(k)=-\infty\end{array}$ & $\begin{array}{l}q^{\prime \prime}(k)_{k \rightarrow k_{\mathrm{j}}}=\frac{-\left(v_{\mathrm{f}}-v_{\mathrm{b}}\right) \theta_{2} \exp \left(\frac{k_{\mathrm{j}}-k_{\mathrm{t}}}{\theta_{1}}\right)}{\theta_{1}\left[1+\exp \left(\frac{k_{\mathrm{j}}-k_{\mathrm{t}}}{\theta_{1}}\right)\right]^{\theta_{2}+1}}\left\{2+\frac{k}{\theta_{1}}\left[1-\frac{\theta_{2}+1}{1+\exp \left(\frac{k_{\mathrm{j}}-k_{\mathrm{t}}}{\theta_{1}}\right)}\right]\right. \\
\text { for given values } q^{\prime \prime}(k)_{k \rightarrow k_{\mathrm{j}}}<0\end{array}$ \\
\hline
\end{tabular}

gradient at jam density and the value must be a negative constant. As we saw in Sect. 3.2.1, $C_{\mathrm{j}}$ values can be estimated by observing platoon dispersion at the signalised intersection and these values are fairly constant for given traffic and road conditions. This property is important in representing the disturbance propagation speed of vehicles in the congested condition. The investigation revealed the following: kinematic wave speed values generated by the linear models are not realistic. At jam density, the values are either equivalent to negative free flow speed or tend to zero. Similarly, Underwood, Drake et al. and Papageorgiou et al.'s models are approaching negative zero. Therefore, they do not satisfy the kinematic wave speed property. The property holds good for Greenberg, Newell, Del Castillo and Lee et al.'s models where the $C_{\mathrm{j}}$ values are negative finite. Further, it is found that Wang et al. model is failing this property by producing negative infinite speed values when density is approaching jam. The kinematic wave speed values are set out in Table 6.

\subsubsection{Stable shock wave property}

This property can be analysed by obtaining the second order derivative of the flow equation with respect to density or by using graphical representation; i.e., convexity (positive sign) must be observed when curve approaching jam density. From the literature, it is observed that this property is important in describing some of the nonlinear behaviour 


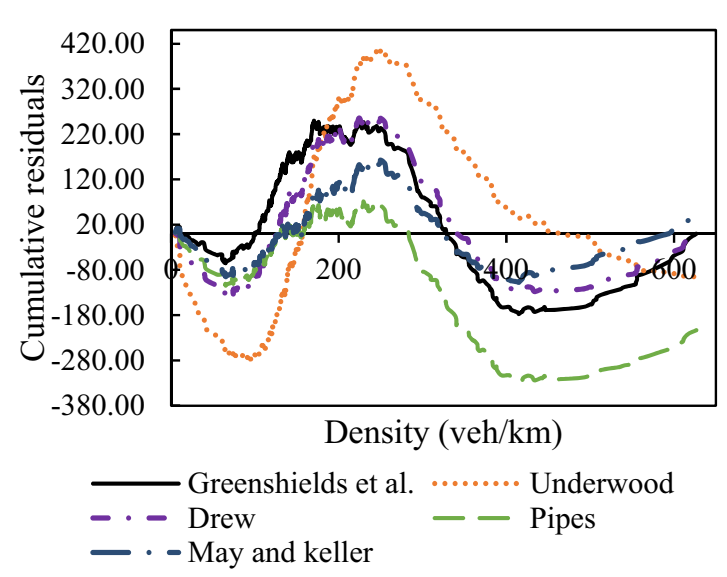

(a)

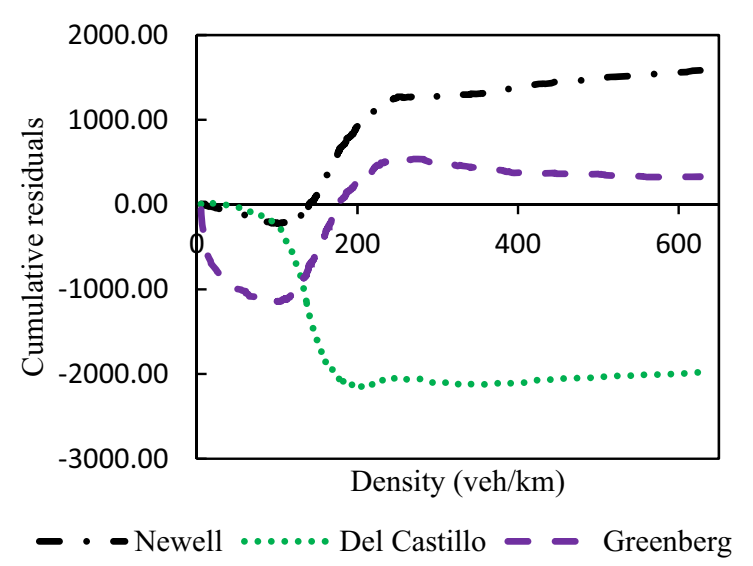

(c)

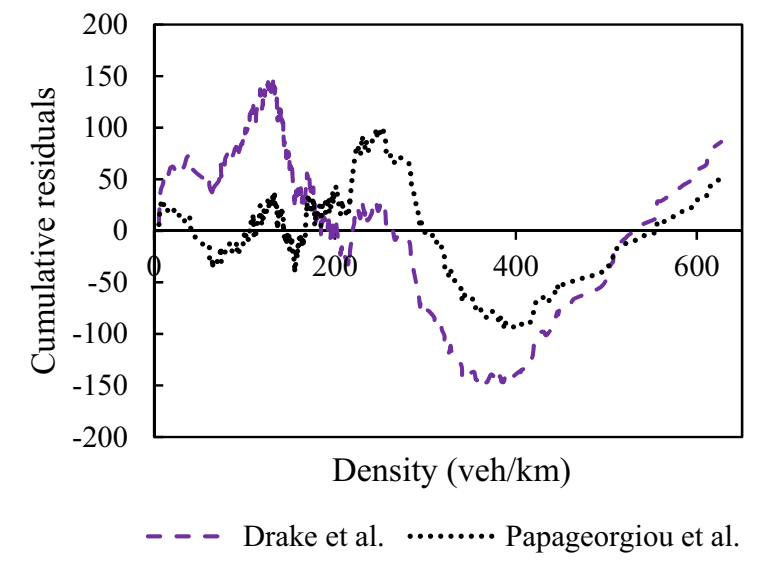

(b)

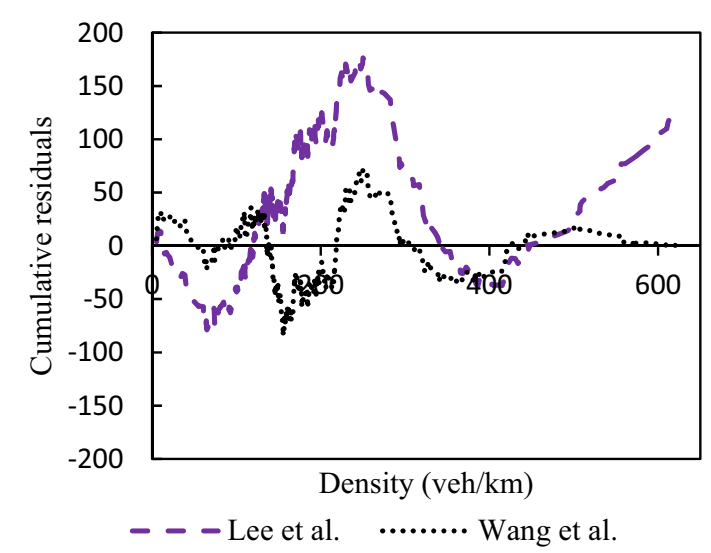

(d)

Fig. 7 CURE plots for a linear models, b Drake et al. and Papageorgiou et al.'s models, c Newell, Del Castillo and Greenberg's models, d Lee et al. and Wang et al.'s models

of traffic flow such as hysteresis, platoon dispersion and density oscillations observed in the congested condition. The analysis results are set out in Table 6 , where models satisfying the stable shock wave property are pointed out with a sign greater than zero and otherwise less than zero.

The analysis shows that the models of Greenshileds et al., Drew, Greenberg, Newell, Del Castillo and Benitez, and Wang et al. are strictly concave and hence unable to satisfy the stable shock wave property. Therefore, it is difficult to explain some of the important traffic flow phenomena, for instance, hysteresis originated in the non- stationary region of the flow-density fundamental diagram. Further, models of Underwood, Drake et al., Papageorgiou et al. and Lee et al. have positive curvature in their subdomain; therefore, they can produce stable shock waves when the vehicles accelerate from a region with high density to a lower density. However, mathematical analysis (Tables 5,6) revealed that none of the existing models satisfies all the properties of the speed-flow-density relationship.

Table 7 Parameters and estimation accuracy of proposed models

\begin{tabular}{|c|c|c|c|c|c|c|c|}
\hline \multirow[t]{2}{*}{ Serial no. } & \multirow[t]{2}{*}{ Model } & \multicolumn{3}{|c|}{ Fundamental parameters } & \multirow[t]{2}{*}{ Shape parameters } & \multirow[t]{2}{*}{ RMSE } & \multirow[t]{2}{*}{ ARE } \\
\hline & & $v_{\mathrm{f}}(\mathrm{km} / \mathrm{h})$ & $k_{\mathrm{j}}(\mathrm{km} / \mathrm{h})$ & Others & & & \\
\hline 1 & Proposed model & 62.9 & 850 & $k_{\mathrm{m}}=360 \mathrm{veh} / \mathrm{h}$ & $a=0.60$ & 4.172 & 0.096 \\
\hline 2 & Modified Lee et al's. model & 63.5 & 900 & - & $E=10.30, \theta=2.14, a=4$ & 4.158 & 0.082 \\
\hline
\end{tabular}




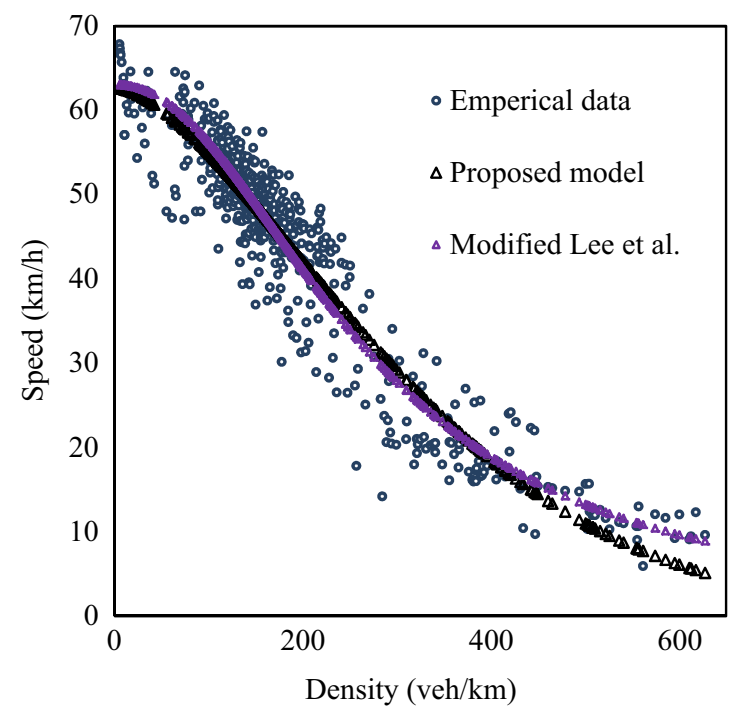

(a)

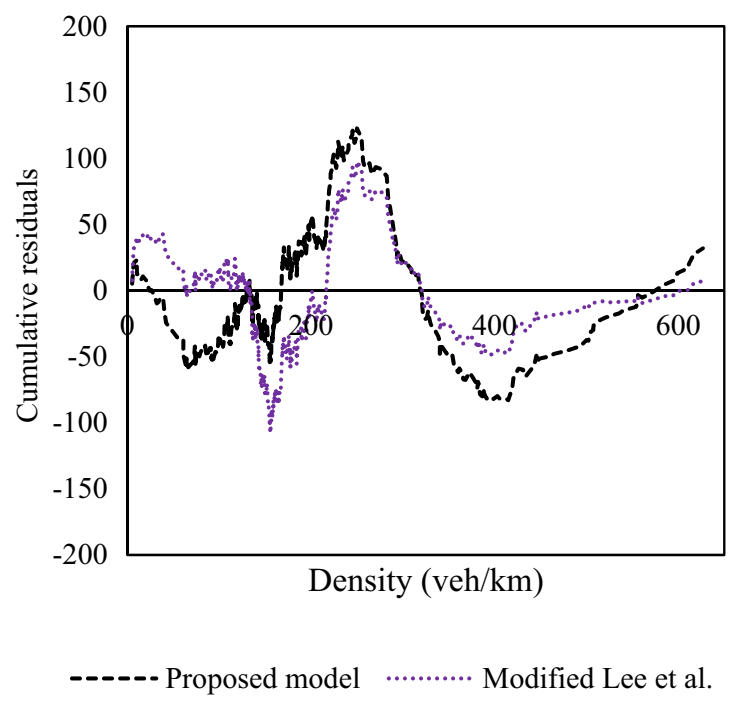

(b)

Fig. 8 Behaviour of proposed speed-density models. a Shape. b Cumulative residuals

\section{Proposed speed-density models}

The limitation of the existing models in satisfying all the properties encouraged us to develop a new speed-density model [Eq. (11)]. The essential requirement for the functional form is that it must satisfy all the properties of the fundamental diagram with a less numerical error. In addition to the new model, a modification has been proposed to the Lee et al.'s model (Eq. (12)) to overcome the deficiencies.

\subsection{The proposed model}

Model formulation is based on the following criteria.

1. The empirical speed-density data show some asymptotic behaviour at the free flow and jam conditions, and also data show a smooth decline in speed values after a critical point. The selection of reciprocal exponential forms is the better representation of this kind of speeddensity relationship. The functional form must be continuous and differentiable.

2. The parameter free flow speed $\left(v_{\mathrm{f}}\right)$ is the property of freely moving traffic and jam density $\left(k_{\mathrm{j}}\right)$ is the property of queueing traffic. Critical density $\left(k_{\mathrm{m}}\right)$ gives an idea on where the traffic condition is changing from free flow state to congested state. These parameters $\left(v_{\mathrm{f}}\right.$, $k_{\mathrm{j}}$ and $k_{\mathrm{m}}$ ) convey some physical meaning.

3. The choice of shape parameters will help in replicating the shape of the data.
4. Importantly, the model must also satisfy all the properties of fundamental diagrams: $v(k)_{k \rightarrow 0}=v_{\mathrm{f}}$, $v(k)_{k \rightarrow k_{\mathrm{j}}}=0, \quad v^{\prime}(0)=0, \quad v^{\prime}(k)<0, \quad q^{\prime}(k)_{k \rightarrow k_{\mathrm{j}}}=-C_{\mathrm{j}}$, $q^{\prime \prime}(k)_{k \rightarrow k_{\mathrm{j}}}>0$.

The model that comes close to satisfying these criteria can take the following form:

$v=v_{\mathrm{f}}\left[\frac{\mathrm{e}^{-\left(\frac{k}{k_{\mathrm{m}}}\right)^{1+a}}-\mathrm{e}^{-\left(\frac{k_{\mathrm{j}}}{k_{\mathrm{m}}}\right)^{1+a}}}{1-\mathrm{e}^{-\left(\frac{k_{\mathrm{j}}}{k_{\mathrm{m}}}\right)^{1+a}}}\right]^{b}$.

Equation (11) gives the general form of the model. Here, $a$ and $b$ are shape parameters.

For $b=1$, the model properties are as follows:

1. At $k=0, v=v_{\mathrm{f}}$.

2. At $k=k_{\mathrm{j}}, v=0$.

3. $v^{\prime}(k)=v_{\mathrm{f}} \frac{\left[-(1+a) \mathrm{e}^{-\left(\frac{k}{k_{\mathrm{m}}}\right)^{1+a}}\left(\frac{k^{a}}{k_{\mathrm{m}}^{1+a}}\right)\right]}{\left[1-\mathrm{e}^{\left.-\left(\frac{k_{\mathrm{j}}}{k_{\mathrm{m}}}\right)^{1+a}\right]}\right.} ; \quad$ at $\quad k=0, \quad v^{\prime}(k)=$ $0 \forall a>0$ satisfies the independent property.

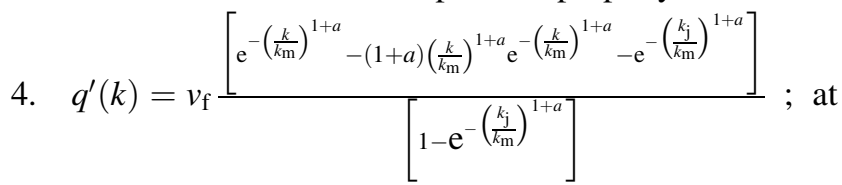
$k \rightarrow \infty, q^{\prime}(k)=-v_{\mathrm{f}}\left[\frac{\mathrm{e}^{-\left(\frac{k_{\mathrm{j}}}{k_{\mathrm{m}}}\right)^{1+a}}}{1-\mathrm{e}^{-\left(\frac{k_{\mathrm{j}}}{k_{\mathrm{m}}}\right)^{1+a}}}\right]$ produces constant negative wave speed. 


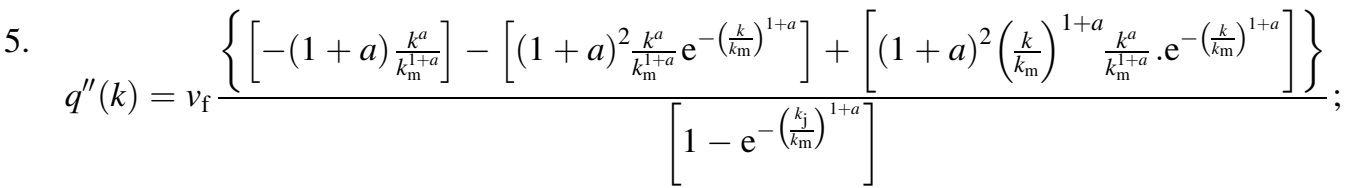

at $k=k_{\mathrm{j}},\left(\frac{k_{\mathrm{j}}}{k_{\mathrm{m}}}\right)^{1+a}>\frac{a+2}{a+1}$, for $a>0$, and $q^{\prime \prime}(k)>0$, produces stable shock waves.

This model satisfies all the properties of flow-speeddensity relationships. The model fitness is also good at $\mathrm{ARE}=0.096$ and $\mathrm{RMSE}=4.172$ except some deviance at the bottom tail. Kinematic wave speed value for given parameter values is $-8 \mathrm{~km} / \mathrm{h}$.

\subsection{Modified Lee et al.'s model}

The shape parameters $a$ and $b$ are introduced into the Lee et al.'s model to overcome the existing deficiencies. The model form is

$v=\frac{v_{\mathrm{f}}\left[1-\left(\frac{k}{k_{\mathrm{j}}}\right)^{a}\right]^{b}}{1+E\left(\frac{k}{k_{\mathrm{j}}}\right)^{\theta}}$

where $E, \theta, a$ and $b$ are shape parameters. In the given model, $a>0$ and $b>0$ conditions hold. For $a>0$ and $b=1$, the model has the following properties:

1. At $k=0, v=v_{\mathrm{f}}$.

2. At $k=k_{\mathrm{j}}, v=0$ for $a>0$.

3. $v^{\prime}(k)=$

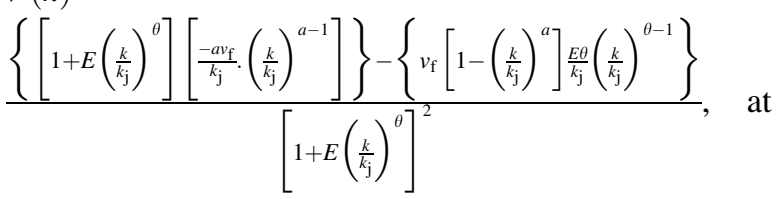

$k=0, \quad v^{\prime}(k)=0$ which satisfies the independent property.

4. $q^{\prime}(k)=\frac{v_{\mathrm{f}}\left[1-(a+1)\left(\frac{k}{k_{\mathrm{j}}}\right)^{a}\right]}{1+E\left(\frac{k}{k_{\mathrm{j}}}\right)^{\theta}}-\frac{\frac{v_{\mathrm{f}} E \theta}{k_{\mathrm{j}}^{\theta}}\left(k^{\theta}-\frac{k^{a+\theta}}{k_{\mathrm{j}}^{a}}\right)}{\left[1+E\left(\frac{k}{k_{\mathrm{j}}}\right)^{\theta}\right]^{2}} ; \quad$ at $\quad k=k_{\mathrm{j}}$, $q^{\prime}(k)=\frac{-a v_{\mathrm{f}}}{1+E}$ is always less than zero for $a>0$, $E>0$. Therefore, kinematic wave speed is a negative constant.

5. $q^{\prime \prime}(k)_{k \rightarrow k_{\mathrm{j}}}=\frac{v_{\mathrm{f}}}{k_{\mathrm{j}}}\left[\frac{E \theta a}{(1+E)^{2}}+\frac{E \theta a}{1+E}-a(a+1)\right]$, for $E>0, \theta>$ $0, a>0 ; q^{\prime \prime}(k)_{k \rightarrow k_{\mathrm{j}}}>0$ produces stable shock waves.

The modified Lee et al.'s model satisfies all the properties of the flow-speed-density relationships with the least error. The RMSE and ARE values for the model are 4.158 and 0.0822 , respectively. For given parameter values, the kinematic wave speed value is $-21.96 \mathrm{~km} / \mathrm{h}$.
Parameter values for the proposed models are given in Table 7. It can be noted that these two proposed models satisfy the static and dynamic properties besides having a high fitting accuracy. Model behaviour with empirical data and CURE plot is shown in Fig. 8. The shape of proposed equilibrium equations has followed the shape of empirical data. We noticed that the model's accuracy could be improved further if parameter $b$ is also considered in these models.

\section{Limitations of this study}

The present study mainly focused on evaluating all the existing single-regime models using two criteria: one is fitting empirical speed-density data and the second is properties of speed-flow-density relationships. It is important to point out that all the analyses and conclusions of this study are conducted based on data collected for a short period of time on a single road section. This may count as a limitation of the study.

\section{Conclusions and future scope}

The purpose of this study is to identify the suitable speeddensity functional form to represent the heterogeneous traffic data. Key findings of this study are as follows:

1. Empirical $v-k$ relationship of heterogeneous traffic observed on urban arterials revealed some interesting facts: (i) Dependence of speed on density is diminished as density approaching zero, i.e. $v^{\prime}(k)_{k \rightarrow 0}=0$, and it is very small compared to homogeneous traffic section. The length of this non-dependency region is generally a function of number of lanes, type of facility and composition of vehicles. (ii) Capacity of the stream is observed to be very high due to the effective utilisation of the road width (this behaviour is possibly attributed to non-lane discipline and the presence of small sized vehicles). (iii) Large variation in highway capacity values can be seen in $q-v$ and $q-k$ plots. Capacity value is ranging from 8000 to $11,000 \mathrm{veh} / \mathrm{h}$. The variation in capacity is observed due to vehicle composition and their respective selection of speeds. (iv) Large deviations (nonlinear behaviour) can be observed in the $q-k$ curve at the congested region. This 
behaviour is attributed to varying vehicle dynamics and their selection of safety headways.

2. As a first attempt for Indian traffic conditions, some of the behavioural parameters such as kinematic wave speed $\left(C_{\mathrm{j}}\right)$ and saturation flow parameter $(\lambda)$ are determined using empirical observations. The typical value of the parameter $C_{\mathrm{j}}$ is $-12.42 \mathrm{~km} / \mathrm{h}$ and the value is less than that of homogenous traffic case [16]. Jam density values for given facilities are difficult to estimate and they approximately vary between 700 and $800 \mathrm{veh} / \mathrm{km}$. The saturation flow parameter value depends on kinematic wave speed and jam density, and the value estimated in the present study is 9000 .

3. In addition to RMSE and ARE, we employed CURE plots to evaluate the overall performance of the models. They revealed some interesting facts: (i) Models of Greenberg, Newell, and Del Castillo and Benitez can be part of multi-regime speed-density models due to their good estimation accuracy at high-density regions. (ii) Linear models of Greenshields et al., Drew and Pipes are poor in representing the data. (iii) Models involving a large number of parameters, for instance, Wang et al.'s model, are sound descriptors of empirical data.

4. The study set out several static and dynamic properties of $q-k-v$ relationships for which the models are examined and compared. The study concludes that none of the existing functional forms can fulfil many of the properties.

5. Two new speed-density functional forms are proposed. From the analysis, it can be concluded that both the proposed models satisfy the numerical accuracy and the fundamental diagram properties. These new forms would be able to improve the model predictions, especially in continuum traffic modelling when in couple with dynamic speed equations.

6. Further, there is a scope for improving the proposed $v$ $k$ relationships by taking model bias and variance into account. In future, it is planned to collect data on more arterial sections to check the compatibility of the proposed models.

Open Access This article is distributed under the terms of the Creative Commons Attribution 4.0 International License (http:// creativecommons.org/licenses/by/4.0/), which permits unrestricted use, distribution, and reproduction in any medium, provided you give appropriate credit to the original author(s) and the source, provide a link to the Creative Commons license, and indicate if changes were made.

\section{References}

1. Lighthill MJ, Whitham GB (1955) On kinematic waves. II. A theory of traffic flow on long crowded roads. Proc R Soc London A 229(1178):317-345
2. Papageorgiou M, Jean-marc B, Hadj-salem H (1989) Macroscopic modelling of traffic flow on the Boulevard Peripherique in Paris. Transp Res Part B Methodol 236(1):29-47

3. Daganzo CF (1994) The cell transmission model: a dynamic representation of highway traffic consistent with the hydrodynamic theory. Transp Res Part B Methodol 28(4):269-287

4. Khan S, Maini P (1999) Modeling heterogeneous traffic flow. Transp Res Rec 1678(1):234-241

5. Tiwari G, Fazio J, Gaurav S (2007) Traffic planning for nonhomogeneous traffic. Sadhana 32(4):309-328

6. Katz D (2009) Heterogeneous traffic mixes,[term paper]. http:// www.donaldkatz.com/CEE6603-TermPaperHeterogeneousTraffic.pdf. Accessed 22 July 2016

7. Greenshields BD, Channing WS, Miller HH (1935) A study of traffic capacity. In: Highway research board proceedings, 1935. National Research Council (USA), Highway Research Board

8. May AD Jr, Harmut EMK (1967) Non-integer car-following models. Highw Res Rec 199:19-32

9. Drew DR (1968) Traffic flow theory and control. McGraw-Hill, New York

10. La Pipes (1967) Car following models and the fundamental diagram of road traffic. Transp Res 1(1):21-29

11. May AD (1990) Traffic flow fundamentals, 2nd edn. Prentice Hall, Englewood Cliffs

12. Greenberg H (1959) An analysis of traffic flow. Oper Res $7(1): 79-85$

13. Underwood RT (1961) Speed, volume, and density relationships: quality and theory of traffic flow. yale Bur Highw traffic 141-188

14. Drake JS, Schofer JL, May Jr AD (1967) A statistical analysis of speed-density hypotheses. In: Vehicular traffic science. Highw Res Rec (154):112-117

15. Newell GF (1961) Nonlinear effects in the dynamics of car following. Oper Res 9(2):209-229

16. Del Castillo JM, Benitez FG (1995) On the functional form of the speed-density relationship-I: general theory. Transp Res Part B Methodol 29(5):373-389

17. Lee HY, Lee HW, Kim D (1998) Origin of synchronized traffic flow on highways and its dynamic phase transitions. Phys Rev Lett 81(5):1130-1133. https://doi.org/10.1103/PhysRevLett.81. 1130

18. Wang H, Li J, Chen QY, Ni D (2010) Representing the fundamental diagram: the pursuit of mathematical elegance and empirical accuracy. In: Transport Research Board 89th annual meeting, Washington, DC, USA

19. Thankappan A, Vanajakshi L (2015) Development and application of a traffic stream model under heterogeneous traffic conditions. J Inst Eng Ser A 96:267-275. https://doi.org/10.1007/ s40030-015-0134-y

20. Heydecker BG, Addison JD (2011) Analysis and modelling of traffic flow under variable speed limits. Transp Res Part C Emerg Technol 19(2):206-217

21. Mallikarjuna C, Phanindra A, Rao KR (2009) Traffic data collection under mixed traffic conditions using video image processing. J Transp Eng 135(4):174-182. https://doi.org/10.1061/ (ASCE)0733-947X(2009)135:4(174)

22. Elzhov TV, Mullen KM, Spiess AN, BolkerB, Mullen MKM (2012) R interface to the Levenberg-Marquardt nonlinear leastsquares algorithm found in MINPACK, plus support for bounds. Retrieved from CRAN: http://cran.rproject.org/web/packages/ minpack.lm/minpack.lm.pdf. Accessed 10 July 2016

23. Hauer E (2015) The art of regression modeling in road safety. Springer, Berlin, p 38 